\title{
Multidisciplinary Approach to Neoadjuvant Endocrine Therapy in Breast Cancer: A Comprehensive Review
}

\section{Abordagem multidisciplinar em hormonioterapia neoadjuvante no câncer de mama: uma revisão}

\author{
Tomás Reinert ${ }^{1,2,3}$ Susana Ramalho ${ }^{4}$ Rodrigo Gonçalves ${ }^{5}$ Carlos Henrique Barrios ${ }^{6}$ \\ Marcia Silveira Graudenz ${ }^{7,8}$ José Bines ${ }^{9}$
}

${ }^{1}$ Department of Medical Oncology, Hospital do Câncer Mãe de Deus,

Address for correspondence Tomás Reinert, MD, CEPESG, Rua Vinte Porto Alegre, RS, Brazil

${ }^{2}$ Centro de Pesquisa da Serra Gaúcha, Caxias do Sul, RS, Brazil de Setembro, 2304, 7 andar, Caxias do Sul, RS, Brazil 95020-450

${ }^{3}$ Post-Graduation Program in Health Sciences, Universidade Federal (e-mail: tomasreinert@hotmail.com).

do Rio Grande do Sul, Porto Alegre, RS, Brazil

${ }^{4}$ Department of Obstetrics and Gynecology, School of Medicine,

Universidade Estadual de Campinas, Campinas, SP, Brazil

${ }^{5}$ Department of Obstetrics and Gynecology, School of Medicine, Universidade de São Paulo, SP, Brazil

${ }^{6}$ School of Medicine, Pontifícia Universidade Católica do Rio Grande do Sul, Porto Alegre, RS, Brazil

7 Pathology Department, Universidade Federal do Rio Grande do Sul, Porto Alegre, RS, Brazil

8 Instituto de Patologia, Porto Alegre, RS, Brazil

${ }^{9}$ Department of Medical Oncology, Instituto Nacional de Câncer, Rio de Janeiro, RJ, Brazil

Rev Bras Ginecol Obstet 2016;38:615-622.

\begin{abstract}
Keywords

- breast neoplasm

- drug therapy

- tamoxifen

- aromatase inhibitors

Breast cancer is the most common type of cancer and the leading cause of cancerrelated death among women worldwide. Hormone receptor-positive (HR+) tumors represent the most common form of this disease, with more than $70 \%$ of breast cancers expressing these receptors. Response and benefit to neoadjuvant chemotherapy (NCT) varies according to HR expression, with lower responses in luminal tumors as compared with hormone receptor-negative (HR-) and human epidermal growth factor receptor 2-positive (HER2+) tumors. Neoadjuvant endocrine therapy (NET) is an option for selected patients with HR+ locally advanced breast cancer. Neoadjuvant endocrine therapy has a favorable toxicity profile, and is associated with benefits such as having low cost and being more easily available even for cancer care professionals outside major urban areas or tertiary centers. These factors are particularly relevant, as $70 \%$ of breast cancer deaths occur in women from lowincome and middle-income countries. Additionally, NET is being increasingly explored, not simply to allow for less extensive surgery, but also as a scientific tool, with the use of biomarkers to predict outcomes in adjuvant trials and for the
\end{abstract}

received July 17, 2016 accepted October 20, 2016 published online December 21, 2016
DOI http://dx.doi.org/ 10.1055/s-0036-1597579. ISSN $0100-7203$.
Copyright $(2016$ by Thieme-Revinter

Publicações Ltda, Rio de Janeiro, Brazil
License terms

(c) (i) $\ominus$ (\$) 


\begin{tabular}{|c|c|}
\hline & $\begin{array}{l}\text { dividual patient. This review details the current and most relevant evidence about } \\
\text { :T for breast cancer as well as the future directions of this field. }\end{array}$ \\
\hline $\begin{array}{l}\text { Palavras-chave } \\
\text { - neoplasias da mama } \\
\text { - farmacoterapia } \\
\text { - tamoxifeno } \\
\text { - inibidores da } \\
\quad \text { aromatase }\end{array}$ & $\begin{array}{l}\text { O câncer de mama é o mais comum, e a principal causa de mortalidade por câncer em } \\
\text { mulheres de todo o mundo. Os tumores com receptor hormonal (RH) positivo } \\
\text { representam o tipo mais comum desta doença. O benefício e as taxas de resposta à } \\
\text { quimioterapia neoadjuvante variam de acordo com a expressão de RH, sendo mais } \\
\text { baixa nos tumores luminais em comparação com tumores HER2 positivos ou triplo- } \\
\text { negativos. A hormonioterapia neoadjuvante, uma opção para pacientes selecionados } \\
\text { com tumores RH positivo localmente avançados, apresenta melhor perfil de tolerabi- } \\
\text { lidade e segurança, e está associada com benefícios adicionais, como baixo custo e fácil } \\
\text { acesso. Estes fatores são relevantes, uma vez que } 70 \% \text { das mortes por câncer de mama } \\
\text { acontecem em mulheres de países pobres ou em desenvolvimento. Além disso, a } \\
\text { hormonioterapia neoadjuvante vem sendo explorada como uma ferramenta científica, } \\
\text { ao possibilitar o estudo de biomarcadores que podem predizer desfechos tanto para } \\
\text { pacientes individuais quanto para ensaios clínicos em adjuvância. Este artigo de revisão } \\
\text { detalha o conhecimento atual e as evidências mais relevantes sobre hormonioterapia } \\
\text { neoadjuvante em câncer de mama, assim como perspectivas futuras nesta área. }\end{array}$ \\
\hline
\end{tabular}

\section{Introduction}

Breast cancer is a heterogeneous group of diseases with different histological, prognostic and clinical aspects. ${ }^{1}$ Hormone receptor positive $(\mathrm{HR}+)$ tumors represent the most common form of breast cancer, and account for most of the deaths from this disease. Modern treatment strategies are tailored to molecular subtypes, ${ }^{2}$ allowing a more individualized approach to therapy.

Early stage breast cancer treatment involves three main therapeutic modalities: surgery, systemic therapy and radiation therapy. Systemic therapies refer to the administration of drugs that spread throughout the body to treat cancer cells wherever they may be. They include chemotherapy, hormonal therapy, immunotherapy, and biologicals such as monoclonal antibodies. Traditionally, systemic therapy has been administered after surgery. Pivotal trials have demonstrated that neoadjuvant (preoperative) chemotherapy (NCT) is safe and equivalent to adjuvant chemotherapy in terms of risk of recurrence and overall survival (OS). ${ }^{3,4}$ Additionally, neoadjuvant chemotherapy induces tumor downstaging and increases the rates of breast-conserving surgery (BCS). ${ }^{5}$

Neoadjuvant endocrine therapy (NET) is an attractive alternative to NCT for estrogen receptor (ER)-positive tumors, given the fact that it is simple to deliver and a welltolerated targeted therapy. The potential of NET is being increasingly explored, not simply to allow for less extensive surgery, but also as a scientific tool, with the use of biomarkers to predict outcomes both in adjuvant trials and for the individual patient. ${ }^{6}$ Although currently available endocrine therapy (ET) agents are generally effective and well-tolerated, not all patients benefit equally. Predictive biomarkers should facilitate a more rational approach to $\mathrm{HR}+$ breast cancer. A better understanding of the features underlying heterogeneity, as well as the mechanisms of resistance to $\mathrm{ET},{ }^{7}$ is essential for the development of novel therapies.

Neoadjuvant treatment modalities require a close collaboration between oncology professionals, including surgeons, gynecologists, medical oncologists, radiation oncologists and pathologists. This review details the current and most relevant evidence about neoadjuvant endocrine therapy for breast cancer, as well as the future directions of this field.

\section{Neoadjuvant Endocrine Therapy as a Clinical Tool}

The development of precision medicine for the treatment of locally advanced breast cancer (LABC) is an appealing concept. The treatment algorithm for $\mathrm{HR}+$ in both the adjuvant and metastatic settings is evolving. Recent developments have elucidated the molecular interactions of HR signaling with other important growth factors: metabolic and cell division pathways. These studies have opened the possibility of improving results while modulating these interactions and interfering with resistance mechanisms. ${ }^{7}$ Therefore, new approaches to treatment have been tested, some of which (that is, the use of genetic signature panels to individualize the adjuvant treatment as well as the use of mechanistic Target of Rapamycin [mTOR] and cyclin-dependent kinase [CDK] 4/6 inhibition) have been incorporated in the clinical practice. ${ }^{8}$ However, despite the developments achieved and the exciting perspectives for the future, we have been unable to fully integrate the concept that different patients have different degrees of endocrine dependency and sensitivity to chemotherapy in the neoadjuvant setting.

It is known that the response and benefit to NCT varies according to HR expression, with lower responses in luminal 
tumors as compared with HR- and HER2+ tumors that are associated with lower pathological complete response (PCR) rates. ${ }^{9,10}$ In patients with luminal tumors, endocrine therapy probably accounts for most of the gains obtained with the adjuvant systemic treatment, and the need for chemotherapy in these patients remains controversial. The absolute OS benefit with adjuvant chemotherapy in postmenopausal women with $\mathrm{HR}+$ breast cancer is no higher than $3-4 \% .{ }^{11}$ Furthermore, data from large phase III trials provide evidence that adjuvant chemotherapy has limited benefits for ER-rich tumors. This view is supported by recent studies of genetic signatures in which the majority of patients with luminal tumors have lowrisk disease and excellent prognosis with adjuvant ET alone.

Neoadjuvant endocrine therapy was initially used in the early 1980 s as a therapeutic option for elderly women who were ineligible for surgery and unfit to be treated with chemotherapy. ${ }^{12}$ Initial studies were designed to evaluate the role of the endocrine treatment as a primary therapeutic option as an alternative to surgery, rather than as a neoadjuvant treatment. ${ }^{13}$ Most of these studies reported response rates of over $50 \%{ }^{12,13}$ A significant higher local regional relapse rate, ${ }^{14}$ and possibly a decrease in $0 S^{15}$ was observed in the group of patients not treated with surgery, although these differences emerged only after a follow-up of a couple of years. ${ }^{16}$ These trials discouraged the use of preoperative ET instead of surgery, but nevertheless showed the approach to be reasonable for patients unfit for surgery. ${ }^{6}$

Modern NET approaches have two main objectives: tumor downstaging to allow for breast-conserving surgery (BCS) and in vivo analysis of sensitivity or resistance to the endocrine treatment. Although endocrine therapy resistance in advanced disease is clinically obvious and is associated with incurability, the detection (or prediction) of ET resistance in primary tumors before relapse remains a crucial research field, because early-stage disease is still within the "curability window". 7

NET has a favorable toxicity profile, especially in comparison with anthracycline and taxane-based chemotherapy. Still, endocrine manipulation is associated with additional potential benefits, such as having low cost and being easily and more rapidly available even for cancer care professionals outside major urban areas or tertiary centers. These factors are particularly relevant, as breast cancer is the most common cancer in women worldwide, and $70 \%$ of breast cancer deaths occur in women from low-income and middle-income countries. ${ }^{17}$ Brazil has a population with diverse ethnic, cultural, and socioeconomic backgrounds, and provision of health care throughout the country is a major challenge.

Nonetheless, it could be stated that there are still more questions than answers regarding NET. The lack of standardized predictive biomarkers and evaluation of the evaluation, the paucity of clinical trials comparing modern NET and NCT strategies, the doubts regarding adjuvant treatment after NET, and the lack of prospective data evaluating the safety of withholding chemotherapy in LABCs are caveats that need to be addressed and constitute a priority for future research within this field.

\section{Current Available Data}

- What is the best endocrine agent?

The third generation aromatase inhibitors (AIs) anastrozole, letrozole and exemestane are currently the standard treatment for HR+ breast cancer when NET is considered. This is also true both in the adjuvant and metastatic settings, based on several clinical trials that demonstrated their superiority over tamoxifen. ${ }^{8,18}$ Randomized clinical trials evaluating this issue in the neoadjuvant setting are summarized in -Table 1. The balance of evidence from the trials shows that AIs are more effective clinically than tamoxifen in achieving response and in down-staging to avoid mastectomy or to convert inoperable tumors into operable ones. ${ }^{19}$ A meta-analysis including a total of 1,160 patients indicated superior outcomes in terms of clinical objective response rate, ultrasound response rate, and BCS rate with AIs when compared with tamoxifen. The American College of Surgeons Oncology Group (ACOSOG) $\mathrm{Z} 1031^{20}$ trial compared exemestane, letrozole and anastrozole head-to-head in the neoadjuvant setting, and showed that the effectiveness of the three agents is equivalent. This question was evaluated in the premenopausal population on the STAGE trial that demonstrated superior response rate, favoring anastrozole plus goserelin in comparison with tamoxifen plus goserelin.

Fulvestrant is a selective estrogen receptor downregulator (SERD) associated with increased progression free survival (PFS) and OS benefits compared with AIs in the first- and second-line treatments of advanced breast cancer. ${ }^{8,21-24}$ However, in a phase II on the neoadjuvant setting, fulvestrant was not superior to standard AI therapy. ${ }^{25}$

- What is the optimal duration?

Based on earlier experience with NCT, a three to fourmonth duration of NET has been proposed in the majority of the clinical trials, such as the Immediate Preoperative Anastrozole, Tamoxifen, or Combined with Tamoxifen (IMPACT), ${ }^{26}$ the Pre-Operative "Arimidex" Compared to Tamoxifen (PROACT) ${ }^{27}$ and the PO24. ${ }^{28}$ However, evidence from other studies suggests that this period may be insufficient to achieve the maximal response in terms of reduction in tumor volume. ${ }^{29-33}$ In summary, these studies investigated the potential benefit of the prolonged treatment with neoadjuvant AIs, and showed that the response rate and the rate of BCS increased after six months of NET, with approximately one third of patients achieving maximal reduction in tumor volume after six months. It must be emphasized that most of the published trials on NET treated patients during $\sim 3-4$ months, thereby potentially underestimating the benefits from the endocrine treatment. It is currently not clear if extending NET to beyond 12 months could further improve the 
Table 1 Randomized trials comparing different endocrine agents in the neoadjuvant setting

\begin{tabular}{|c|c|c|c|c|c|}
\hline $\begin{array}{l}\text { Trial (ref) } \\
\text { phase }\end{array}$ & Treatment arm (n) & $\begin{array}{l}\text { Duration } \\
\text { (months) }\end{array}$ & Primary endpoint & ORR & BCS \\
\hline $\begin{array}{l}\text { IMPACT }^{26} \\
\text { III }\end{array}$ & $\begin{array}{l}\text { A: Anastrozole (113) } \\
\text { B: Tamoxifen (108) } \\
\text { C: Anastrozole }+ \text { tamoxifen (109) }\end{array}$ & 3 & ORR by ultrasound & $\begin{array}{l}\text { A: } 37 \% \\
\text { B: } 36 \% \\
C: 39 \%\end{array}$ & $\begin{array}{l}A: 44 \% \\
B: 31 \% \\
C: 29 \%\end{array}$ \\
\hline $\begin{array}{l}\mathrm{PO} 24^{52} \\
\text { III }\end{array}$ & A: Letrozole (162)B: Tamoxifen (223) & 4 & ORR by clinical palpation & $\begin{array}{l}\text { A: } 55 \%^{*} \\
\text { B: } 36 \% \\
p<0.001\end{array}$ & $\begin{array}{l}\text { A: } 45 \% * \\
\text { B: } 35 \% \\
p=0.02\end{array}$ \\
\hline $\begin{array}{l}\text { PROACT }^{27} \\
\text { III }\end{array}$ & $\begin{array}{l}\text { A: Anastrozole }(228) \\
\text { B: Tamoxifen }(223)\end{array}$ & 3 & ORR by ultrasound & $\begin{array}{l}\text { A: } 39 \% \\
\text { B: } 35 \%\end{array}$ & $\begin{array}{l}\text { A: } 43 \%^{*} \\
\text { B: } 31 \% \\
p=0.04\end{array}$ \\
\hline $\begin{array}{l}\text { ACOSOG Z1011 } \\
\text { II }\end{array}$ & $\begin{array}{l}\text { A: Exemestane (124) } \\
\text { B: Letrozole }(128) \\
\text { C: Anastrozole (125) }\end{array}$ & 4 & ORR by clinical palpation & $\begin{array}{l}\text { A: } 63 \% \\
\text { B: } 75 \% \\
C: 69 \%\end{array}$ & $\begin{array}{l}\text { A: } 48 \% \\
\text { B: } 41 \% \\
\text { C: } 64 \%\end{array}$ \\
\hline $\begin{array}{l}\text { STAGE }_{\text {III }}^{20} \\
\text { ST }\end{array}$ & $\begin{array}{l}\text { A: Anastrozole (+ goserelin) (98) } \\
\text { B: Tamoxifen (+ goserelin) }(98)\end{array}$ & 6 & ORR by caliper & $\begin{array}{l}\text { A: } 70 \% \\
\text { B: } 50 \% \\
p=0.004\end{array}$ & $\begin{array}{l}\text { A: } 86 \% \\
\text { B: } 68 \%\end{array}$ \\
\hline $\begin{array}{l}\text { RUSSIAN TRIAL } \\
\text { II }\end{array}$ & $\begin{array}{l}\text { A: Exemestane (76) } \\
\text { B: Tamoxifen (75) }\end{array}$ & 3 & ORR by clinical palpation & $\begin{array}{l}\text { A: } 76 \%^{*} \\
\text { B: } 40 \% \\
p=0.05\end{array}$ & $\begin{array}{l}\text { A: } 37 \% \\
\text { B: } 25 \% \\
p=0.05\end{array}$ \\
\hline $\begin{array}{l}\text { CARMINA }^{25} \\
\text { II }\end{array}$ & $\begin{array}{l}\text { A: Anastrozole (57) } \\
\text { B: Fulvestrant } 500 \mathrm{mg}(59)\end{array}$ & $4-6$ & ORR by clinical palpation & $\begin{array}{l}\text { A: } 62 \% \\
\text { B: } 46 \%\end{array}$ & $\begin{array}{l}\text { A: } 59 \% \\
\text { B: } 49 \%\end{array}$ \\
\hline
\end{tabular}

Abbreviations: BCS, breast-conserving surgery; CARMINA; IMPACT, Immediate Preoperative Anastrozole, Tamoxifen, or Combined with Tamoxifen; ORR, overall response rate; PO24; PROACT, Pre-Operative "Arimidex" Compared to Tamoxifen; STAGE.

response, but there is a theoretical risk that mechanisms of resistance to AI therapy ${ }^{7}$ could develop during the treatment, triggering the event of tumor progression and even disease spread beyond the breast. ${ }^{34}$

\section{- NET versus NCT?}

There is very limited data comparing NCT and NET, ${ }^{19}$ and the best available evidence comes from two randomized phase II trials ( - Table 2). Semiglazov et $\mathrm{al}^{35}$ randomized 239 postmenopausal women with stage IIA-IIIB HR + breast cancer to receive preoperative AIs (anastrozole or exemestane for three months) or chemotherapy (four cycles of doxorubicin plus paclitaxel). ${ }^{35}$ There was no statistically significant difference between NET and NCT in terms of clinical response rate, time to response, and pCR. The Grupo Español de Investigación en Cáncer de Mama (GEICAM) 2006-03 trial randomized 97 patients with immunohistochemistry (IHC)-defined luminal disease to receive neoadjuvant exemestane (a small proportion of premenopausal patients also received goserelin) for six months or chemotherapy (Adriamycin [doxorubicin]/cyclophosphamide [AC] followed by docetaxel). Although no statistically significant difference was found between the two arms in terms of response rate, there was a trend for a worse outcome in the endocrine therapy arm for premenopausal patients and those with high expression of tumor Ki67. ${ }^{36}$ The Neoadjuvant Chemotherapy Versus Endocrine Therapy (NEOCENT) trial, ${ }^{37}$ which was designed to address this

Table 2 Randomized trials comparing endocrine versus chemotherapy in the neoadjuvant setting

\begin{tabular}{|c|c|c|c|c|c|}
\hline Trial (ref) & Treatment arm (n) & Duration & Primary endpoint & ORR & BCS \\
\hline Semiglazov et $\mathrm{al}^{35}$ & $\begin{array}{l}\text { A: Chemotherapy (118) } \\
\text { (doxorrubicin + paclitaxel) } \\
\text { B: Endocrine therapy (121) } \\
\text { (anastrozole 61) (Exemestane 60) }\end{array}$ & 3 months & ORR by clinical palpation & $\begin{array}{l}\text { A:63\% } \\
\text { B: } 64 \%\end{array}$ & $\begin{array}{l}\text { A: } 24 \% \\
\text { B: } 33 \% \\
p=0.058\end{array}$ \\
\hline GEICAM 2006-0336 & $\begin{array}{l}\text { A: Chemotherapy } \\
\text { (EC-> docetaxel) } \\
\text { B: Exemestane } \\
\text { (plus goserelin if premenopausal) }\end{array}$ & & Response rate by MRI & $\begin{array}{l}\text { A: } 66 \% \\
\text { B: } 48 \%\end{array}$ & $\begin{array}{l}\text { A: } 47 \% \\
\text { B: } 56 \%\end{array}$ \\
\hline NEOCENT ${ }^{37}$ & $\begin{array}{l}\text { A: Chemotherapy (22) } \\
\text { B: letrozole (22) }\end{array}$ & $18-23$ weeks & $\begin{array}{l}\text { Recruitment feasibility } \\
\text { and tissue collection }\end{array}$ & $\begin{array}{l}\text { A: } 54 \% \\
\text { B: } 59 \%\end{array}$ & \\
\hline
\end{tabular}

Abbreviations: BCS, breast-conserving surgery; EC, epirrubicin + cyclophosphamide; GEICAM, Grupo Español de Investigación en Cáncer de Mama; MRI, magnetic resonance imaging; NEOCENT, neoadjuvant chemotherapy versus endocrine therapy; ORR, overall response rate. 
important question (comparing NCT and NET), was unfortunately closed due to slow accrual. Given the evidence regarding the modest efficacy of chemotherapy for HR+ disease in both the adjuvant and the neoadjuvant settings, and the feasibility, efficacy and activity of NET, a comparison of NCT and NET in the context of HR-rich disease is required, and should be considered a priority in breast cancer clinical research.

- NET in premenopausal patients

Data are very limited on NET in premenopausal women. A Japanese trial compared the efficacy of anastrozole with goserelin versus tamoxifen with goserelin for 24 weeks preoperatively in 197 premenopausal patients with ER+ HER2- early breast cancer. The overall response rate was $70.4 \%$ in the anastrozole group. This finding correlates with the recently reported practicechanging Suppression of Ovarian Function Trial (SOFT) 38 and Tamoxifen and Exemestane Trial (TEXT), ${ }^{39}$ which demonstrated a significant benefit in terms of recurrence-free survival for ovarian function suppression plus an AI in comparison with tamoxifen in premenopausal patients with high-risk early breast cancer. These results are encouraging, and suggest that an AI plus ovarian function suppression is an effective treatment option in this patient population. However, until this question is adequately evaluated in large prospective randomized trials, NET in premenopausal patients should be considered experimental.

\section{Neoadjuvant Endocrine Therapy in 2016 take home messages}

- Ideal candidates: postmenopausal patients with ER-enriched stage II-III breast cancer

- Als superior to tamoxifen

- Anastrozole, letrozole and exemestane are equivalent

- Optimal duration: 6 months (at least)

- Clinical response rate $=50-70 \%$

- Downstaging to BCS $=30-50 \%$

\section{Outcomes and Response Evaluation in NET}

Neoadjuvant systemic therapy (NAST) provides valuable information for patients, clinicians and researchers. However, there is significant variability in the methods of the pathological assessment of the response to the neoadjuvant systemic treatment, and therefore, there is also significant variability in their interpretation for subsequent clinical decisions. Pathological complete response (PCR), defined as the absence of invasive disease in both the breast and the lymph nodes, is frequently considered an intermediate endpoint to predict the long-term outcome following NCT. Recently, the US Food and Drug Administration (FDA) has recommended $\mathrm{pCR}$ as an endpoint for the accelerated approval of new agents for neoadjuvant treatment for high-risk early-stage breast cancer, and has recently approved pertuzumab based on the increase in the $\mathrm{pCR}$ rate. ${ }^{40}$ International collaboration groups have published recommendations for the standardized pathological characterization of residual disease for the neoadjuvant clinical trials of breast cancer. The use of pCR to demonstrate the treatment efficacy of novel therapies requires a standard definition and approach to pCR assessment. A standard approach to the post-NAST pathological assessment of breast cancer would improve comparisons between clinical trials and enable the accumulation of more robust evidence in controversial areas of practice, such as specimen handling, and better serve each patient. Unfortunately, there is paucity of evidence and recommendations regarding the pathological evaluation after NET.

In the meta-analysis of the Collaborative Trials in Neoadjuvant Breast Cancer (CTNeoBC), patients who achieved pCR had a $52 \%$ reduction in the probability of an event $(p<0.001)$ and a $64 \%$ reduction in the probability of death $(p<0.001) .{ }^{41}$ The achievement of $\mathrm{PCR}$ was highly variable by tumor subtype, with aggressive tumor subtypes more likely associated with event-free survival than smaller, less aggressive tumors. Pathological complete responses were more uncommon in patients with low-grade HR+ tumors (7\%) than among patients with tumors that were highgrade $\mathrm{HR}+(16 \%)$, triple-negative (34\%), HR + /HER2+ (30\%), and HR-/HER2 + (50\%). The Food and Drug Administration accepts two definitions of $\mathrm{pCR}$ as an endpoint to support accelerated drug approval: $y p \mathrm{TO} y p \mathrm{NO}$ (that is, absence of residual invasive and in situ cancer in the breast and axillary lymph nodes following the completion of the neoadjuvant therapy) and $y p \mathrm{T0} / \mathrm{Tis} y p \mathrm{NO}$ (absence of residual invasive cancer in the breast and lymph nodes, irrespective of ductal carcinoma in situ [DCIS]). Eventfree survival and OS were shown similar for ypT0 and $y p$ TO/Tis ypNO. Residual DCIS was not associated with the prognostic value. ${ }^{41}$

Pathological complete remissions are infrequent with NET and, as such, have not demonstrated prognostic or predictive value. Some systems, such as the Residual Cancer Burden $(\mathrm{RCB})^{42}$ index, are used to quantify the amount of cancer remaining after treatment, and are being incorporated into research protocols. Is has been demonstrated that patients with minimal invasive residual disease have a better prognosis in comparison with patients with higher volume of residual disease after NCT, demonstrating a pattern of resistance to systemic therapy. This interesting approach, however, has not been validated after endocrine treatment.

Interestingly, and in contrast to NCT, preoperative AIs have been reported as producing the histological feature of central scarring with a statistically significant correlation between central scarring and clinical tumor volume reduction. ${ }^{43}$ This observation requires validation, but, if confirmed, central scarring could be explored as a surrogate predictive endpoint.

The pathologist plays a key role in determining the extent and types of response to therapy. To achieve the maximum amount of information, careful pretreatment tumor and 
lymph node sampling, and close communication among the surgeon, the medical oncologist, the radiologists and the pathologist is mandatory.

\section{Neoadjuvant Endocrine Therapy as a Scientific Tool}

Besides the advantages discussed before, NET can be a very useful scientific tool. The evaluation of treatment response in vivo is of the utmost importance, especially when the disease is still potentially curable. A crucial aspect in the use of NET is how to determine treatment success. It has been discussed previously how $\mathrm{PCR}$ is not a good parameter to determine the response to NET, and how it is not a good predictive and prognostic marker in this setting. With that in mind, Ellis et $\mathrm{al}^{28}$ in the early 2000's, developed a research strategy to evaluate the response to NET based on intuitive methods used in the clinical management of patients. As a patient is diagnosed with high blood pressure, a clinician would start him on a drug, losartan for example, and then measure the patient's blood pressure after a few days or weeks and evaluate treatment success.

Using this logical approach, Ellis' group investigated the utility of Ki-67 as a possible predictive biomarker to treatment response. Ki-67 is one of the most widely used proliferation markers in breast cancer. The relationships between Ki-67 and outcomes are greatly clarified when Ki-67 levels are measured after the initiation of the neoadjuvant endocrine therapy. ${ }^{28,44,45}$ In 2008 , Ellis et $\mathrm{al}^{28}$ published the preoperative endocrine prognostic index (PEPI) score, including tumor size, nodal status, ER status and Ki-67 score. Patients that achieved a PEPI score of 0 after 16-18 weeks of NET were considered to have very low risk of relapse, and weren't likely to benefit from adjuvant chemotherapy. The PEPI score was then evaluated on the Z1031 trial that randomized 377 post-menopausal, stage II and III, ER+ breast cancer patients to receive NET. The time to breast cancer recurrence was decreased among those with PEPI $>0$ status relative to those with PEPI-0 status. Only one disease event among 44 (2\%) cases with PEPI-0 was observed, versus 26 out of 158 cases (16.5\%) with PEPI $>0$. This study showed the PEPI score is a valid clinical trial endpoint to identify patients with very low relapse risk after NET, and, therefore, it has operational characteristics similar to pCR after chemotherapy for ER- disease. ${ }^{46}$ On an extension of the Z1031 trial, the group activated the $\mathrm{Z} 1031$ trial cohort B. In that arm, the group developed a strategy to evaluate the response to NET in which, after 2-4 weeks of ET, patients would have another biopsy to evaluate Ki-67 and other parameters. With a Ki-67 higher than $10 \%$, patients would be considered resistant to ET, and would be triaged to either NCT or surgery; if $\mathrm{Ki}-67$ was lower than $10 \%$, patients would be considered sensitive to NET, and would complete 16-18 weeks of NET. They concluded that a Ki67 value $>10 \%$ at 2 to 4 weeks strongly enriches for high-risk molecular subtypes (mainly luminal B [LumB]), and should be managed with the addition of chemotherapy to their treatment plan. The results of the longer follow-up of that trial are expected in $2016 .^{47}$
In 2012, Goncalves et $\mathrm{al}^{48}$ evaluated another interesting feature of Ki-67 in the NET setting. By comparing adjuvant and neoadjuvant endocrine treatment trials, the authors identified a very provocative pattern. Based on the pharmacodynamic property of Ki-67 while on endocrine treatment, that is, the reduction of Ki-67, results of small, shorter, less expensive NET trials predicted with surprising accuracy the results of adjuvant trials that were longer (requiring at least 5 years of follow-up) and required thousands of patients, being, therefore, very expensive. At a time in which the cost of research is increasingly higher and research funding is limited, the activation of an adjuvant endocrine treatment trial should be preceded by promising results in the neoadjuvant setting.

\section{Future Perspectives}

Neoadjuvant endocrine therapy trials are the ideal scenario to study biomarkers, and much has been accomplished using Ki67, ER status and PEPI score. Besides prognostic information (PEPI score) and better patient selection (ER and Ki67), NET also identifies endocrine resistant tumors whose prognosis might only be improved through the combination with target therapies or with chemotherapy. Most of the current available target therapies have been investigated in association with endocrine therapy on metastatic patients in mixed endocrine resistance stages (endocrine naïve, acquired resistance and de novo resistance). The ongoing NET trials using endocrine therapy combined with various target agents (CDK inhibitors, mTOR inhibitors, phosphoinositide 3-kinase [PI3K] inhibitors and HER2 targets) have the advantage of addressing endocrine naïve patients, optimizing the study of biomarker development with tumor tissue analysis and treatment efficacy assessment.

One of the main limitations of NET trials is their small sample size due to patient selection and the general fear of tumor progression during NET. The collection of biological material is usually performed at 2 or 3 time periods during the neoadjuvant treatment to allow for pre-treatment and on-treatment biomarker analysis and evaluation of prognostic and predictive factors. ${ }^{49}$ The acquisition of on-treatment specimens is also a valuable resource for genomic profiling studies that will enlighten us on the mutational background of treatment-responsive and treatment-resistant tumors, possibly leading to more tailored strategies. ${ }^{50}$

\section{Conclusion}

Chemotherapy has been the mainstay modality in the neoadjuvant treatment of breast cancer since the landmark National Surgical Adjuvant Breast and Bowel Project (NASBP) B-18 trial, which compared the same anthracycline-based regimen in the adjuvant and the neoadjuvant settings. ${ }^{4}$ Since then, the characterization of breast cancer subtypes has directed us to a more rational treatment approach to the disease. The chemotherapy strategy is particularly adequate for triple-negative breast cancers and for HER2 + disease (in combination with anti-HER2 agents), with a consistent high pCR. At the same time, 
the added benefit of chemotherapy for the larger and heterogeneous HR+ subgroup has been challenged.

Neoadjuvant endocrine therapy is a rational approach that provides an outstanding opportunity to further individualize treatment selection. However, it has been timidly evaluated in the clinical trials, and implemented rarely in the clinical practice. According to the National Cancer Database, in the US, only $3 \%$ of the eligible patients receive this therapy. ${ }^{51}$

The multiple breast cancer molecular profiles and their translation into usable tumor and serum platforms may provide the basis for NET. At the same time, the remarkable improvement recently demonstrated, and the ongoing research in advanced breast cancer with the combination of endocrine agents with PI3K and CDK inhibitors will likely be incorporated in earlier stage diseases. An increased impetus to NET is likely to come in the following years.

\section{Methods Supplement}

Selected trials included in a recently published systematic review and meta-analysis were evaluated.19A descriptive synthesis was planned, as we did not expect the data to be sufficiently homogeneous to allow for direct comparisons and definitive statements. Our objective was to perform a comprehensive review focused on the most important patient care related aspects. Based on Preferred Reporting Items for Systematic Reviews and Meta-Analyses (PRISMA) guidelines, Spring et $\mathrm{al}^{19}$ selected twenty prospective, randomized, neoadjuvant clinical trials that reported response rates with at least one arm incorporating NET.

In our analysis, ten studies were considered: three studies comparing NET monotherapy with AIs and combination NCT for localized breast cancer, and seven studies comparing NET monotherapy with different endocrine agents. Trials evaluating NET with growth factor pathway inhibitors and studies without direct comparison were not included.

\section{Acknowledgments}

TR, SR and RG gratefully acknowledge Dr. Matthew Ellis for the mentorship that led to the conception of this manuscript.

\section{References}

1 Zardavas D, Irrthum A, Swanton C, Piccart M. Clinical management of breast cancer heterogeneity. Nat Rev Clin Oncol 2015; 12(7):381-394

2 Kravchenko J, Akushevich I, Seewaldt VL, Abernethy AP, Lyerly HK. Breast cancer as heterogeneous disease: contributing factors and carcinogenesis mechanisms. Breast Cancer Res Treat 2011; 128(2):483-493

3 Mauri D, Pavlidis N, Ioannidis JP. Neoadjuvant versus adjuvant systemic treatment in breast cancer: a meta-analysis. J Natl Cancer Inst 2005;97(3):188-194
4 Fisher B, Bryant J, Wolmark N, et al. Effect of preoperative chemotherapy on the outcome of women with operable breast cancer. J Clin Oncol 1998;16(8):2672-2685

5 Eiermann W, Pienkowski T, Crown J, et al. Phase III study of doxorubicin/cyclophosphamide with concomitant versus sequential docetaxel as adjuvant treatment in patients with human epidermal growth factor receptor 2-normal, node-positive breast cancer: BCIRG-005 trial. J Clin Oncol 2011;29(29):3877-3884

6 Smith IE. Preoperative endocrine therapy for operable breast cancer. In: Harris JR, Lippman ME, Morrow M, Osborne CK, editors. Diseases of the breast. 5th ed. Philadelphia: Wolters Kluwer; 2014:754-763

7 Ma CX, Reinert T, Chmielewska I, Ellis MJ. Mechanisms of aromatase inhibitor resistance. Nat Rev Cancer 2015;15(5):261-275

8 Reinert T, Barrios CH. Optimal management of hormone receptor positive metastatic breast cancer in 2016. Ther Adv Med Oncol 2015;7(6):304-320

9 Colleoni M, Viale G, Zahrieh D, et al. Chemotherapy is more effective in patients with breast cancer not expressing steroid hormone receptors: a study of preoperative treatment. Clin Cancer Res 2004;10(19):6622-6628

10 Guarneri V, Broglio K, Kau SW, et al. Prognostic value of pathologic complete response after primary chemotherapy in relation to hormone receptor status and other factors. J Clin Oncol 2006; 24(7):1037-1044

11 Peto R, Davies C, Godwin J, et al; Early Breast Cancer Trialists' Collaborative Group (EBCTCG). Comparisons between different polychemotherapy regimens for early breast cancer: meta-analyses of long-term outcome among 100,000 women in 123 randomised trials. Lancet 2012;379(9814):432-444

12 Preece PE, Wood RA, Mackie CR, Cuschieri A. Tamoxifen as initial sole treatment of localised breast cancer in elderly women: a pilot study. Br Med J (Clin Res Ed) 1982;284(6319):869-870

13 Gazet JC, Markopoulos C, Ford HT, Coombes RC, Bland JM, Dixon RC. Prospective randomised trial of tamoxifen versus surgery in elderly patients with breast cancer. Lancet 1988;1(8587):679-681

14 Bates T, Riley DL, Houghton J, Fallowfield L, Baum M; The Elderly Breast Cancer Working Party. Breast cancer in elderly women: a Cancer Research Campaign trial comparing treatment with tamoxifen and optimal surgery with tamoxifen alone. Br J Surg 1991;78(5):591-594

15 Fennessy M, Bates T, MacRae K, Riley D, Houghton J, Baum M. Late follow-up of a randomized trial of surgery plus tamoxifen versus tamoxifen alone in women aged over 70 years with operable breast cancer. Br J Surg 2004;91(6):699-704

16 Mustacchi G, Ceccherini R, Milani S, et al; Italian Cooperative Group GRETA. Tamoxifen alone versus adjuvant tamoxifen for operable breast cancer of the elderly: long-term results of the phase III randomized controlled multicenter GRETA trial. Ann Oncol 2003;14(3):414-420

17 Lee BL, Liedke PE, Barrios CH, Simon SD, Finkelstein DM, Goss PE. Breast cancer in Brazil: present status and future goals. Lancet Oncol 2012;13(3):e95-e102

18 Dowsett M, Forbes JF, Bradley R, et al; Early Breast Cancer Trialists' Collaborative Group (EBCTCG). Aromatase inhibitors versus tamoxifen in early breast cancer: patient-level meta-analysis of the randomised trials. Lancet 2015;386(10001):1341-1352

19 Spring LM, Gupta A, Reynolds KL, et al. Neoadjuvant endocrine therapy for estrogen receptor-positive breast cancer a systematic review and meta-analysis. JAMA Oncol 2016;2(11):1477-1486

20 Ellis MJ, Suman VJ, Hoog J, et al. Randomized phase II neoadjuvant comparison between letrozole, anastrozole, and exemestane for postmenopausal women with estrogen receptor-rich stage 2 to 3 breast cancer: clinical and biomarker outcomes and predictive value of the baseline PAM50-based intrinsic subtype-ACOSOG Z1031. J Clin Oncol 2011;29(17):2342-2349

21 Robertson JF, Llombart-Cussac A, Rolski J, et al. Activity of fulvestrant $500 \mathrm{mg}$ versus anastrozole $1 \mathrm{mg}$ as first-line 
treatment for advanced breast cancer: results from the FIRST study. J Clin Oncol 2009;27(27):4530-4535

22 Robertson JF, Llombart-Cussac A, Felti D, et al. Fulvestrant $500 \mathrm{mg}$ versus anastrozole as first-line treatment for advanced breast cancer: overall survival from the phase II 'first' study (Abstract). In: Proceedings of the San Antonio Breast Cancer Symposium; 2014 Dec 9-13; San Antonio, USA. p. S6-04.

23 Di Leo A, Jerusalem G, Petruzelka L, et al. Results of the CONFIRM phase III trial comparing fulvestrant $250 \mathrm{mg}$ with fulvestrant $500 \mathrm{mg}$ in postmenopausal women with estrogen receptor-positive advanced breast cancer. J Clin Oncol 2010;28(30):4594-4600

24 Di Leo A, Jerusalem G, Petruzelka L, et al. Final overall survival: fulvestrant $500 \mathrm{mg}$ vs $250 \mathrm{mg}$ in the randomized CONFIRM trial. J Natl Cancer Inst 2014;106(1):djt337

25 Lerebours F, Bourgier C, Alran S, Mouret-Fourme E. Abstract PD07-04: A randomized phase II neoadjuvant trial evaluating anastrozole and fulvestrant efficiency for post-menopausal ERpositive, HER2-negative Breast Cancer patients: first results of the UNICANCER CARMINA 02 French trial. Cancer Res 2012;72(24, Suppl)PD07-PD04

26 Smith IE, Dowsett M, Ebbs SR, et al; IMPACT Trialists Group. Neoadjuvant treatment of postmenopausal breast cancer with anastrozole, tamoxifen, or both in combination: the Immediate Preoperative Anastrozole, Tamoxifen, or Combined with Tamoxifen (IMPACT) multicenter double-blind randomized trial. J Clin Oncol 2005;23(22):5108-5116

27 Cataliotti L, Buzdar AU, Noguchi S, et al. Comparison of anastrozole versus tamoxifen as preoperative therapy in postmenopausal women with hormone receptor-positive breast cancer: the PreOperative "Arimidex" Compared to Tamoxifen (PROACT) trial. Cancer 2006;106(10):2095-2103

28 Ellis MJ, Tao Y, Luo J, et al. Outcome prediction for estrogen receptor-positive breast cancer based on postneoadjuvant endocrine therapy tumor characteristics. J Natl Cancer Inst 2008; 100(19):1380-1388

29 Dixon JM, Renshaw L, Macaskill EJ, et al. Increase in response rate by prolonged treatment with neoadjuvant letrozole. Breast Cancer Res Treat 2009;113(1):145-151

30 Llombart-Cussac A, Guerrero Á, Galán A, et al. Phase II trial with letrozole to maximum response as primary systemic therapy in postmenopausal patients with $\mathrm{ER} / \mathrm{PgR}[+]$ operable breast cancer. Clin Transl Oncol 2012;14(2):125-131

31 Fontein DB, Charehbili A, Nortier JW, et al. Efficacy of six month neoadjuvant endocrine therapy in postmenopausal, hormone receptor-positive breast cancer patients-a phase II trial. Eur J Cancer 2014;50(13):2190-2200

32 Krainick-Strobel UE, Lichtenegger W, Wallwiener D, et al. Neoadjuvant letrozole in postmenopausal estrogen and/or progesterone receptor positive breast cancer: a phase IIb/III trial to investigate optimal duration of preoperative endocrine therapy. BMC Cancer 2008;8:62

33 Carpenter R, Doughty JC, Cordiner C, et al. Optimum duration of neoadjuvant letrozole to permit breast conserving surgery. Breast Cancer Res Treat 2014;144(3):569-576

34 Barroso-Sousa R, Silva DD, Alessi JV, Mano MS. Neoadjuvant endocrine therapy in breast cancer: current role and future perspectives. Ecancermedicalscience 2016;10:609

35 Semiglazov VF, Semiglazov VV, Dashyan GA, et al. Phase 2 randomized trial of primary endocrine therapy versus chemotherapy in postmenopausal patients with estrogen receptorpositive breast cancer. Cancer 2007;110(2):244-254

36 Alba E, Calvo L, Albanell J, et al; GEICAM. Chemotherapy (CT) and hormonotherapy (HT) as neoadjuvant treatment in luminal breast cancer patients: results from the GEICAM/2006-03, a multicenter, randomized, phase-II study. Ann Oncol 2012;23(12):3069-3074

37 Palmieri C, Cleator S, Kilburn LS, et al. NEOCENT: a randomised feasibility and translational study comparing neoadjuvant endocrine therapy with chemotherapy in ER-rich postmenopausal primary breast cancer. Breast Cancer Res Treat 2014;148(3):581-590

38 Francis PA, Regan MM, Fleming GF, et al; SOFT Investigators; International Breast Cancer Study Group. Adjuvant ovarian suppression in premenopausal breast cancer. N Engl J Med 2015; 372(5):436-446

39 Pagani O, Regan MM, Walley BA, et al; TEXT and SOFT Investigators; International Breast Cancer Study Group. Adjuvant exemestane with ovarian suppression in premenopausal breast cancer. N Engl J Med 2014;371(2):107-118

40 Gianni L, Pienkowski T, Im YH, et al. Efficacy and safety of neoadjuvant pertuzumab and trastuzumab in women with locally advanced, inflammatory, or early HER2-positive breast cancer (NeoSphere): a randomised multicentre, open-label, phase 2 trial. Lancet Oncol 2012;13(1):25-32

41 Cortazar P, Zhang L, Untch M, et al. Pathological complete response and long-term clinical benefit in breast cancer: the CTNeoBC pooled analysis. Lancet 2014;384(9938):164-172

42 Symmans WF, Peintinger F, Hatzis C, et al. Measurement of residual breast cancer burden to predict survival after neoadjuvant chemotherapy. J Clin Oncol 2007;25(28):4414-4422

43 Thomas JS, Julian HS, Green RV, Cameron DA, Dixon MJ. Histopathology of breast carcinoma following neoadjuvant systemic therapy: a common association between letrozole therapy and central scarring. Histopathology 2007;51(2):219-226

44 Dowsett M, Smith IE, Ebbs SR, et al; IMPACT Trialists Group. Prognostic value of Ki67 expression after short-term presurgical endocrine therapy for primary breast cancer. J Natl Cancer Inst 2007;99(2):167-170

45 Dowsett M, Smith IE, Ebbs SR, et al; IMPACT Trialists. Short-term changes in Ki-67 during neoadjuvant treatment of primary breast cancer with anastrozole or tamoxifen alone or combined correlate with recurrence-free survival. Clin Cancer Res 2005;11(2 Pt 2): 951s-958s

46 Sanati S, Suman VJ, Goncalves R, DeSchryver K, Ma CX, Hoog J, et al. Validation of the preoperative endocrine prognostic index in the ACOSOG (Alliance) Z1031 neoadjuvant aromatase inhibitor trial [abstract P4]. Cancer Res 2015;75(9, Suppl):11-13

47 Ellis MJ, Suman V, McCall L, et al. Z1031B: neoadjuvant aromatase inhibitor trial: a phase 2 study of triage to chemotherapy based on 2 to 4 week Ki67 level > 10\%. Cancer Res 2012;72(24, Suppl):PD07-PD01

48 Goncalves R, Ma C, Luo J, Suman V, Ellis MJ. Use of neoadjuvant data to design adjuvant endocrine therapy trials for breast cancer. Nat Rev Clin Oncol 2012;9(4):223-229

49 López-Knowles E, Gao Q Cheang MC, et al; POETIC trialists. Heterogeneity in global gene expression profiles between biopsy specimens taken peri-surgically from primary ER-positive breast carcinomas. Breast Cancer Res 2016;18(1):39

50 Dowsett M, Smith I, Robertson J, et al. Endocrine therapy, new biologicals, and new study designs for presurgical studies in breast cancer. J Natl Cancer Inst Monogr 2011;2011(43):120-123

51 Semiglazov V, Kletsel V, Semiglazov V, et al. Exemestane (E) vs tamoxifen $(\mathrm{T})$ as neoadjuvant endocrine therapy for postmenopausal women with ER+ breast cancer (T2N1-2, T3N0-1, T4N0M0). J Clin Oncol 2005;23(16, Suppl):530

52 Chiba A. Neoadjuvant endocrine use in the U.S. for hormone receptor positive breast cancer: results from the National Cancer Data Base. Abstract of the Society of Surgical Oncology Annual Cancer Symposium; 2016. Abst. 19.

53 Eiermann W, Paepke S, Appfelstaedt J, et al; Letrozole NeoAdjuvant Breast Cancer Study Group. Preoperative treatment of postmenopausal breast cancer patients with letrozole: A randomized double-blind multicenter study. Ann Oncol 2001;12(11):1527-1532

54 Masuda N, Sagara Y, Kinoshita T, et al. Neoadjuvant anastrozole versus tamoxifen in patients receiving goserelin for premenopausal breast cancer (STAGE): a double-blind, randomised phase 3 trial. Lancet Oncol 2012;13(4):345-352 